\title{
REPRESENTATIVENESS OF EUROPEAN BIOCHAR RESEARCH: PART I - FIELD EXPERIMENTS
}

\author{
Frank G. A. VERHEIJEN ${ }^{\mathrm{a}}$, Utra MANKASINGH ${ }^{\mathrm{b}}$, Vit PENIZEK ${ }^{\mathrm{c}}$, Pietro PANZACCHI ${ }^{\mathrm{d}}$, Bruno GLASER \\ Simon JEFFERY ${ }^{\mathrm{f}}$, Ana Catarina BASTOS ${ }^{\mathrm{g}}$, Priit TAMMEORG ${ }^{\mathrm{h}}$, Jürgen KERN ${ }^{\mathrm{i}}$, \\ Costanza ZAVALLONI, Giulia ZANCHETTIN ${ }^{\mathrm{k}}$, Ruben SAKRABANI ${ }^{1}$
}

aDepartment of Environment and Planning and Centre for Environmental and Marine Studies (CESAM), University of Aveiro, Campus Universitário de Santiago, 3810-193 Aveiro, Portugal

${ }^{b}$ Institute of Life and Environmental Sciences, University of Iceland, Sturlugata 7, Reykjavik 101, Iceland ${ }^{c}$ Česká Zemèdělská Univerzita v Praze, Fakulta Agrobiologie Potravinových a Přírodních Zdrojů, Kamýcká 129, 16521 Praha 6-Suchdol, Czech Republic

${ }^{d}$ Faculty of Science and Technology, Free University of Bolzano/Bozen, piazza Università, 5-39100 Bolzano, Italy

'Institute of Agronomy and Nutritional Sciences, Soil Biogeochemistry,

Martin Luther University Halle-Wittenberg, von-Seckendorff-Platz 3, 06120 Halle, Germany

${ }^{f}$ Crop and Environment Sciences department, Harper Adams University, Newport, Shropshire, TF10 8NB, United Kingdom

sDepartment of Biology and Centre for Environmental and Marine Studies (CESAM), University of Aveiro, Campus Universitário de Santiago, 3810-193 Aveiro, Portugal

${ }^{h}$ Department of Agricultural Sciences, P.O. Box 27 (Latokartanonkaari 5, Plant Production Sciences), FIN-00014 University of Helsinki, Finland

${ }^{i}$ Leibniz Institute for Agricultural Engineering and Bioeconomy, Max-Eyth Allee 100, 14469 Potsdam, Germany ${ }^{j}$ California State University Stanislaus, Agricultural Studies program, One University Circle, Turlock, CA 95382, USA ${ }^{k}$ Department of Agricultural and Environmental Sciences, University of Udine, via delle Science 208, 33100, Udine, Italy 'School of Water, Energy and Environment, Cranfield Soil and Agrifood Institute, Cranfield University, MK43 OAL United Kingdom

Submitted 1 Jun. 2016; accepted 07 March 2017

\begin{abstract}
A representativeness survey of existing European Biochar field experiments within the Biochar COST Action TD1107 was conducted to gather key information for setting up future experiments and collaborations, and to minimise duplication of efforts amongst European researchers. Woody feedstock biochar, applied without organic or inorganic fertiliser appears over-represented compared to other categories, especially considering the availability of crop residues, manures, and other organic waste streams and the efforts towards achieving a zero waste economy. Fertile arable soils were also over-represented while shallow unfertile soils were under-represented. Many of the latter are likely in agroforestry or forest plantation land use. The most studied theme was crop production. However, other themes that can provide evidence of mechanisms, as well as potential undesired side-effects, were relatively well represented. Biochar use for soil contamination remediation was the least represented theme; further work is needed to identify which specific contaminants, or mixtures of contaminants, have the potential for remediation by different biochars.
\end{abstract}

Keywords: biochar, soil, Europe, field experiments, representativeness.

Online supplementary material: Supporting information for this paper is available as online supplementary material at https://doi.org/10.3846/16486897.2017.1304943

Corresponding author: Frank G. A. Verheijen

E-mail: frankverheijen@gmail.com 


\section{Introduction}

Biochar is the solid product of heating biomass in the absence of, or with limited access to, oxygen - a process called pyrolysis (Lehmann, Joseph 2015) with the primary goal of soil amendment. The objective of biochar use is to abate the enhanced greenhouse effect by sequestering $\mathrm{C}$ in soils, while concurrently improving soil quality (Glaser et al. 2002; Lehmann 2007). Biochar is more recalcitrant than the original material: carbon from biochar is estimated to persist in soils for hundreds of years, while non-pyrolysed biomass carbon turns over in the range of decades (Gurwick et al. 2013; Wang et al. 2015). Together with carbon sequestration, biochar is intended to improve soil properties, such as water and nutrient retention as well as improved soil structure and drainage (Glaser et al. 2002; Jeffery et al. 2011; Abrol et al. 2016).

Current biochar research is fragmented, unnecessarily repeated, and new scientific evidence is often not connected or implemented due to the lack of interaction and knowledge exchange. European scholars decided to consolidate biochar research and technology across Europe. For this purpose, a pan-European Cooperation in Science and Technology (COST) project was launched in 2012: "Biochar as option for sustainable resource management" (TD1107). The main focus of this project was to establish a European Biochar Research Network to formulate synergies and reduce redundancies. This COST Action connected scattered European biochar research to facilitate implementation of sustainable material flow management systems according to the Circular Economy principle. In essence, the goal of biochar application is to maintain or improve soil quality while efficiently sequestering carbon in the long-term. Innovative biochar strategies can help the EU mitigate greenhouse gases, while industries and farmers benefit from new markets, opportunities and improving poor soils. Therefore, this project aimed to bring together researchers, stakeholders and potential users from EU and partner countries.

Biochar addition to soil has been shown to affect soil properties and functions in several ways. Key soil chemical and physical characteristics such as $\mathrm{pH}, \mathrm{CEC}$, structure, field capacity, and surface albedo are affected by the presence of biochar with consequences for nutrient cycling, plant growth and soil fauna activity (Ameloot et al. 2013; Glaser et al. 2002; Lehmann, Joseph 2015; Verheijen et al. 2010, 2013). In order to attempt a successful assessment of the current level of scientific understanding (LOSU) of biochar's effect on soil properties and functions, working groups 2 and 4 proposed the development of crosscutting thematic groups (TGs) within the Biochar COST Action. As a rationale for the individual TGs, the EU list of threats to soil (i.e. erosion, decline in SOM, compaction, decline in soil biodiversity, salinization, contamination;
Eckelmann et al. 2006) was combined with the main soil functions and services (i.e. habitat, production and regulation) and with the main scientific disciplines involved (i.e. physical, chemical and biological). Six TGs (Suppl. Table 1) where thus created and voluntarily filled with experts from within the COST Action and additionally included invited experts when needed.

Growing interest and research in biochar applications to soils have increased steadily in the last 10 years (Verheijen et al. 2014; Lehmann, Joseph 2015). The number of publications of experimental studies investigating biochar application to soil and subsequent effects have increased almost exponentially since 2009, from 53 between 2005 and 2009 to more than 1,800 publications from 2010 to present, with almost a third of these being carried out by EU28 scientists (SCOPUS search for the terms "biochar" and "soil"). These include systems level (field) and reductionist (pot/lab) studies, and the growth of these over last 10 years has trebled.

Development of effective sustainable policy requires a sufficient Level of Scientific Understanding, or LOSU. When the LOSU can be considered sufficient is much discussed (Tammeorg et al. 2017; this issue), although it is generally agreed that a mechanistic understanding is required in addition to a systems level understanding of effects. For either, the LOSU needs to comprehensively cover the dependent variable (e.g. biochar characteristics), as well as the independent variables (i.e. soils, climates, land use and land management; Verheijen et al. 2012, 2015). The first step in developing the LOSU for biochar is to determine how representative the knowledge base is regarding production and environmental application.

The aim of this representativeness survey was to provide a snapshot of the current field trial locations in the EU, the associated analyses that were carried out (soils, crops, climates, and biochars). A representativeness survey can be used to identify the spread of existing experiments that can cover various important factors: i) biochars; ii) geographical locations; iii) environmental properties (soil, climate, crop, terrain); and iv) land use/land management combinations. In this way, it is possible to find out if effects are studied in all combinations of the main factors (comprehensive representation), and more intensively in more common combinations of variables (proportional representation). This information can then be used to direct further research to fill missing knowledge gaps. To the best of our knowledge, the current representativeness survey on biochar effects in the environment is unique for an EU wide context.

The objective of the work described in this paper was i) to determine how comprehensive the current experimental sites are in terms of feedstock, geography, environmental variables, land use \& land management variables, 
and ii) to suggest recommendations to harmonise the current field experiments to increase representativeness.

\section{Methods and materials}

\subsection{Biochar COST action}

The characteristics of COST Actions are new, innovative and often interdisciplinary scientific networks, which contribute to the scientific, economic, cultural and societal development of Europe. Networking is supported by meetings, conferences, short-term scientific missions (STSM), and training schools. A COST Action is based on a Memorandum of Understanding (MoU) accepted by the Governments of at least 5 COST member countries. COST is organised in nine broad Domains, which are specified at http://www.cost.eu.

Since the COST Action "Biochar as option for sustainable resource management" (Fig. 1) could be related to the two domains 1) Earth System Science and Environmental Management and 2) Food and Agriculture, finally it was considered as a Trans-Domain COST Action, which offers researchers fertile ground for future networks across many science and technology disciplines.

When the COST Action TD1107 was approved in December 2011, there were seven participating countries (Austria, Germany, Israel, Latvia, Spain, Switzerland, and the United Kingdom). Belgium and Finland intended to participate at that time. During the first meeting the Management Committee consisting of up to two representatives from 18 countries, which had accepted the MoU in the meantime, came together in Brussels on 26th March 2012. That was the beginning of the period of validity of this COST Action. Year by year, new countries from Europe and associated countries joined the Action. During the final period (August 2015), in total 29 countries

Management committee: 29 participating countries Steering committee: Action chair and vice chair, Wps managers, STSM manager, gender balance manager, external experts.

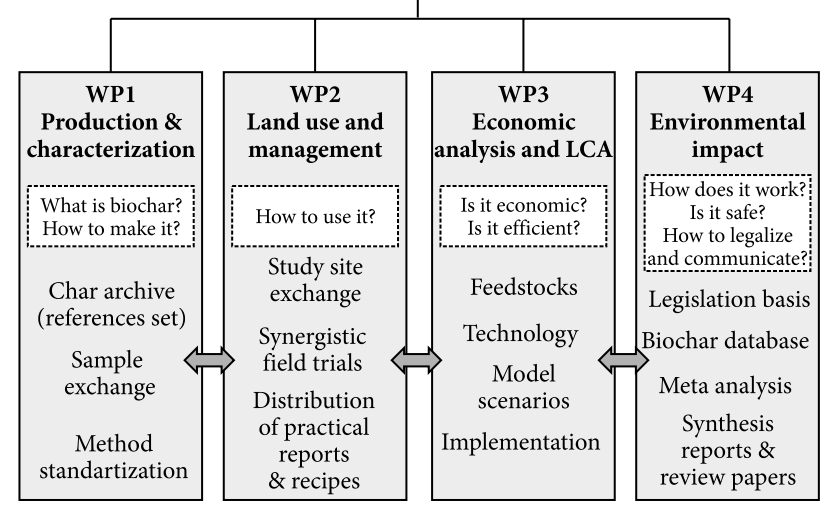

Fig. 1. Organization of EU COST Action TD1107: Biochar as option for sustainable resource management. For more details see the website of the European Biochar Research Network: http://cost.european-biochar.org were participating the COST Action TD1107 (Suppl. Table 2). The COST Action was organised into four Working Groups, whose leaders formed the Steering Committee together with the chair, the vice-chair, and the STSM manager (Suppl. Table 3).

\subsection{Biochar experiment survey}

The initial survey consisted of an Excel spreadsheet where participants were asked to provide information in five main areas, i.e. A - General (4 questions); B - Field data (before biochar addition; 49 questions); C - Biochar properties (35 questions); D - Indication of measured effect (31 questions); and E - Publications (2 questions). Units were specified in a separate column where appropriate. Drop-down menus were used where possible to standardise responses. A "free text" column was inserted to allow comments from the participants.

To improve convenience for submission of surveys, an online web form was set up in October 2014. Using the Drupal Web form module, a web form was designed covering the questions from the Excel spreadsheet. In contrast to the Excel spreadsheet, some questions were split into two or organized in different main areas. In total, the web form consisted of 10 (A-General), 50 (B-Field data), 34 (C-Biochar properties), 32 (D-Indication of measured effect), and 1 (E-Publications) questions. It was operated from the European Biochar Research Network (EBRN) server and the URL to the web form was distributed among COST members via e-mail and through the Internet app Basecamp. In February 2015, all online submissions were exported to Excel and merged with the initial Excel spreadsheets. Draft submissions from the web form and duplicate submissions were removed from the data set. In total, 67 submissions were collected and used for further data analysis. During data collection, some data loss occurred, e.g. two field studies from Finland were lost from the final database. The database refers to studies that were active sometime during the period 2013-2015. Information on the continuation of field site monitoring is not available.

\subsection{Spatial representation of soil, climate and land use of the EU28}

The extent of current soil cover, climatic region and land use distribution in the EU28 were assessed using a set of spatial databases. The European Soil Database (ESDB 2.0 2004) was used to describe the spatial occurrence of soil units. Because of the high complexity of the soil classification units within the database, the soil grouping was simplified into 10 groups based on the main character of soil development (Table 1). Arenosols and Regosols were grouped into "non-developed soils" and Chernozems, Phaeozems, Kastanozems and Vertisols into "mollic soils". 
Soil units with a spatial proportion less than $1 \%$ were omitted. The climatic region characterisation was based on the updated Köppen climatic map (Peel et al. 2007) using 2nd level of Köppen classification. In total, five classification units were recognized within the EU28 (Table 1). For land use, the CORINE classification system with the first classification level was used (EEA 2016). In total, six classes with a spatial extent higher than $1 \%$ were recognised (Table 1).

\section{Results}

\subsection{Inventory of main biochar characteristics and application strategies}

Table 2 provides an overview of the feedstock types and production temperatures of the biochars used in the field experiments. The majority (64\%) used lignocellulosic feedstock, 30\% used herbaceous feedstock, and 7\% used a biosolid feedstock. Of the field sites, 75\% used biochar produced between 450 and $649{ }^{\circ} \mathrm{C}$, while $13 \%$ used lower temperature $\left(<450{ }^{\circ} \mathrm{C}\right)$, and $11 \%$ higher temperatures $\left(>649^{\circ} \mathrm{C}\right)$. Lignocellulosic (i.e. woody) feedstock produced between $450-649{ }^{\circ} \mathrm{C}$ was by far the most common combination (46\%); twice as common as herbaceous feedstock produced at $450-649^{\circ} \mathrm{C}(23 \%)$, with the remaining combinations representing $11 \%$ or less of the total.

Figure 2 shows that the production technologies were split between slow pyrolysis $\left(400-750{ }^{\circ} \mathrm{C}\right)$ and retort kiln $\left(350-550{ }^{\circ} \mathrm{C}\right)$ on the one hand $(48 \%)$ and fast pyrolysis $\left(400-620^{\circ} \mathrm{C}\right)$ and gasification $\left(1200{ }^{\circ} \mathrm{C}\right)$ on the other $(43 \%)$. Ninety-six percent of the biochars had an ash content below $50 \%$. The majority of the biochars had a $\mathrm{pH}$ between 8.1 and 10.0, and nearly a quarter of the biochars were highly alkaline $(\mathrm{pH}>10.0)$. Most of the field sites used biochar with a relatively low CEC $(<20 \mathrm{cmol}+/ \mathrm{kg})$, with an equal split $(18 \%)$ between the 20-60 and $>60(\mathrm{cmol}+/ \mathrm{kg})$ categories.

The majority of field sites incorporated (mixed) biochar into the topsoil, although $28 \%$ applied biochar in a minimum tillage soil management system, e.g. disking, thereby only semi-incorporating the biochar into the soil (Fig. 3). This was reflected in the biochar application depth, where $0-10 \mathrm{~cm}$ was used most frequently (41\%)

Table 1. Classes of climate, soil type, and land use that were selected for the representativeness analysis. For soils and climates, \% indicates the proportion of the EU28 agricultural area. For land use, \% indicates the proportion of the EU28 land area

\begin{tabular}{|c|c|c|c|c|c|c|c|c|}
\hline \multicolumn{3}{|l|}{ Climate } & \multicolumn{3}{|c|}{ Soil } & \multicolumn{3}{|l|}{ Land use } \\
\hline & Code & $\%$ & & Code & $\%$ & & Code & $\%$ \\
\hline Cold, without dry season & Df & 51 & Cambisols & $\mathrm{CM}$ & 30 & Forests & 31 & 35 \\
\hline $\begin{array}{l}\text { Temperate, without dry } \\
\text { season }\end{array}$ & $\mathrm{Cf}$ & 29 & Podzols & $\mathrm{PZ}$ & 20 & Arable land-non irrigated & 21 & 30 \\
\hline Temperate, dry summer & Cs & 12 & Luvisols & LV & 16 & $\begin{array}{l}\text { Scrub and/or herbaceous } \\
\text { vegetation }\end{array}$ & 32 & 11 \\
\hline Arid steppe & BS & 5 & Leptosols & LP & 9 & $\begin{array}{l}\text { Heterogeneous } \\
\text { agricultural areas }\end{array}$ & 24 & 10 \\
\hline Polar & $\mathrm{E}$ & 2 & Non-developed soils & ND & 5 & Pastures & 23 & 9 \\
\hline \multirow[t]{6}{*}{ Other } & - & 03 & Fluvisols & FL & 5 & Permanent crops & 22 & 3 \\
\hline & & & Mollic soils & $\mathrm{MO}$ & 5 & Other & - & 2 \\
\hline & & & Histosols & HS & 5 & & & \\
\hline & & & Gleysoils & GL & 3 & & & \\
\hline & & & Albeluvisols & $A B$ & 2 & & & \\
\hline & & & Other & - & 1 & & & \\
\hline
\end{tabular}

Table 2. Feedstock type and production temperature overview. Lignocellulosic includes woody materials. Herbaceous includes crop residue, green waste and silage. Biosolids include manures, sewage, and liquid organic waste. Carbonisation $\mathrm{T}$ refers to the maximum temperature reached during the carbonisation (pyrolysis) process. 61 out of 67 studies reported feedstock and production temperature data

\begin{tabular}{l|ccc|ccc|ccc}
\hline \multicolumn{1}{c|}{ Feedstock type } & \multicolumn{3}{c|}{ Lignocellulosic } & \multicolumn{3}{c|}{ Herbaceous } & \multicolumn{3}{c}{ Biosolids } \\
\hline Production T $\left({ }^{\circ} \mathrm{C}\right)$ & $<450$ & $450-649$ & $>649$ & $<450$ & $450-649$ & $>649$ & $<450$ & $450-649$ & $>649$ \\
\hline Number of field sites & 7 & 28 & 4 & 1 & 14 & 3 & 0 & 4 & 0 \\
\hline Feedstock type (\%) & 18 & 72 & 10 & 6 & 78 & 17 & 0 & 100 & 0 \\
\hline Total proportion of sites (\%) & 11 & 46 & 7 & 2 & 23 & 5 & 0 & 7 & 0 \\
\hline
\end{tabular}


compared to $0-20(34 \%)$ and $0-30(25 \%)$. The resulting biochar concentration in the soil was roughly equally split between $<1 \%$ and $\geq 1 \%$ (w/w), although it should be noted that only $25 \%$ of the field sites in the database had this variable reported. Most field sites (77\%) used pure biochar with only $19 \%$ using treated biochar, i.e. enriched with nutrients (fertiliser) or by co-addition with compost or inoculated with microorganisms. The experimental design of $84 \%$ of the field sites was either fully randomised or random block, and 66\% used field plots between 10 and $100 \mathrm{~m}^{2}$ with $12 \%$ using plots $<1 \mathrm{~m}^{2}$ and $3 \%$ using plots $>100 \mathrm{~m}^{2}$ (data not shown).
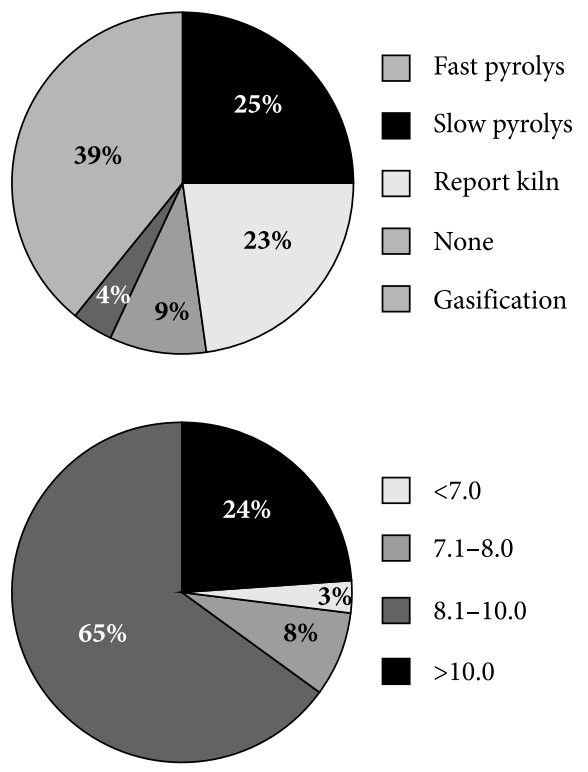

\subsection{Geographical and climatic representativeness}

Table 3 shows the number of biochar field sites in the Biochar COST Action countries. Slovakia has both the greatest total number of field sites (12) as well as the most field sites per $100,000 \mathrm{~km}^{2}(24.9)$. Belgium is second with 5 field sites $\left(16.5 / 100,000 \mathrm{~km}^{2}\right)$, followed by a group of countries with 4-6 sites $/ 100,000 \mathrm{~km}^{2}$, namely: The Netherlands, Estonia, and the UK. A third group of five countries has $1.5-3$ sites $/ 100,000 \mathrm{~km}^{2}$, and a fourth group has fewer than 1.5 sites $/ 100,000 \mathrm{~km}^{2}$.

Figure 4 shows how the representation of experimental sites within EU28 agricultural area climatic regions
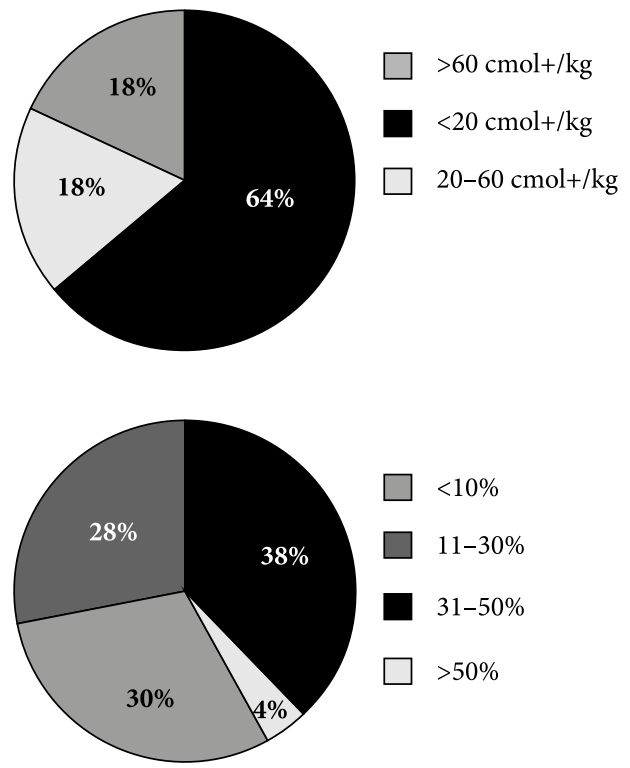

Fig. 2. Overview of biochar production technologies and main biochar properties in Europe (Feb. 2015): Production technology (top left, $\mathrm{n}=67$ ); biochar CEC (top right, $\mathrm{n}=11$ ); biochar $\mathrm{pH}$ (bottom left, $\mathrm{n}=62$ ); biochar ash content (bottom right, $\mathrm{n}=47$ )
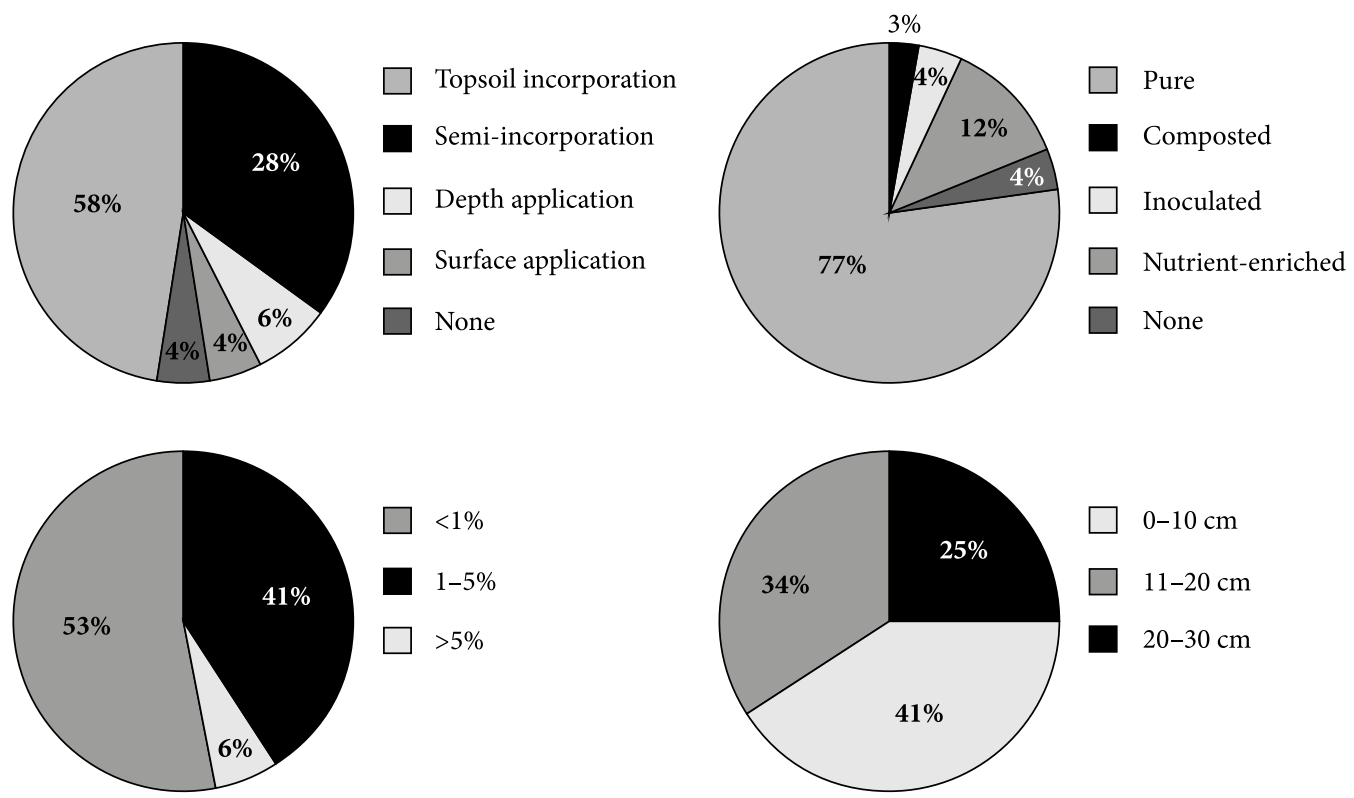

Fig. 3. Overview of biochar application strategies in Europe (Feb. 2015): application strategy (top left, $\mathrm{n}=66$ ); biochar treatment (top right, $\mathrm{n}=66$ ); biochar concentration in soil (bottom left; $\mathrm{n}=17$ ); application depth (bottom right, $\mathrm{n}=66$ ) 
(Table 1) by Biochar COST Action field sites. The arid steppe and polar climate categories are not represented at all, mainly due to limited amounts of agriculture being undertaken in these areas. The temperate climate without dry season and cold climate without dry summer are the most represented. Temperate climate with dry summer is strongly over-represented.

\subsection{Land use representativeness}

Figure 5 shows how well the main land use types (Table 1) are represented by the Biochar COST Action field sites. Heterogeneous agricultural areas, scrub and herbaceous vegetation, and open spaces with little or no vegetation are not represented at all. Forests are strongly, and pastures moderately, under-represented. Permanent crops are strongly, and arable land (irrigated and non-irrigated) moderately, over-represented.

\subsection{Soil representativeness}

Figure 6 shows how the main soil types of the EU28 agricultural land area (Table 1) are represented by the COST Action field sites. Leptosols, Non-developed soils, and Histosols are not represented at all. Mollisols, Fluvisols, and Podzols are strongly under-represented. Luvisols and Albeluvisols are strongly over-represented. Cambisols and Gleysols are the best represented soil types.

Table 3. Distribution of biochar field sites by countries in the COST Action. Countries are arranged by the number of field sites per 100,000 $\mathrm{km}^{2}$ land area (not including water bodies). Countries without field sites are not listed (Feb. 2015)

\begin{tabular}{lcc}
\hline Country & $\begin{array}{c}\text { Total Number } \\
\text { of field sites }\end{array}$ & $\begin{array}{c}\text { Number of field sites per } \\
100,000 \mathrm{~km}^{2} \text { land area }\end{array}$ \\
\hline Slovakia & 12 & 24.9 \\
\hline Belgium & 5 & 16.5 \\
\hline Netherlands & 2 & 5.9 \\
\hline Estonia & 2 & 4.7 \\
\hline United Kingdom & 11 & 4.5 \\
\hline Italy & 8 & 2.7 \\
\hline Austria & 2 & 2.4 \\
\hline Denmark & 1 & 2.4 \\
\hline Poland & 7 & 2.2 \\
\hline Spain & 9 & 1.8 \\
\hline Portugal & 1 & 1.1 \\
\hline Finland & 3 & 0.9 \\
\hline Germany & 2 & 0.6 \\
\hline Norway & 1 & 0.3 \\
\hline France & 2 & 0.3 \\
\hline Russia & 1 & 0.0 \\
\hline
\end{tabular}

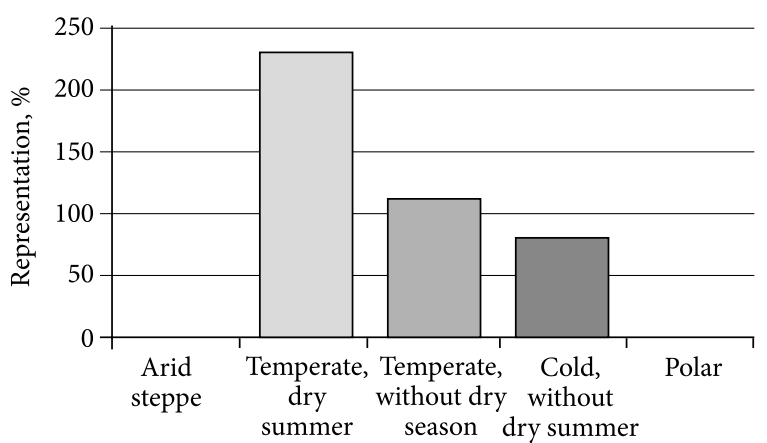

Fig. 4. Climatic representativeness of the COST action field sites vs. the EU28 agricultural area. 100\% means that the proportion of field sites is the same as the proportion in the EU28 agricultural area. A representation value $>100 \%$ indicates over-representation, and a value $<100 \%$ indicates underrepresentation (Feb. 2015)

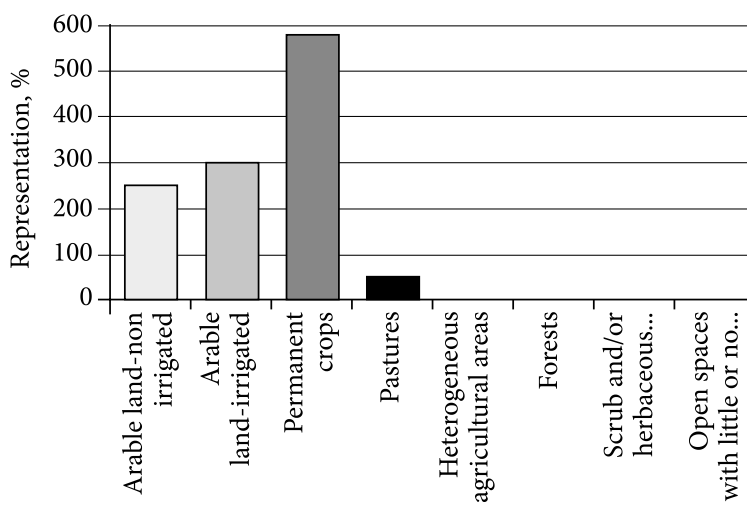

Fig. 5. Land use representativeness of the COST action field sites vs. the EU28 agricultural area. 100\% means that the proportion of field sites is the same as the proportion of the agricultural area for the EU28. A representation value $>100 \%$ indicates over-representation, and a value $<100 \%$ indicates under-representation (Feb. 2015)

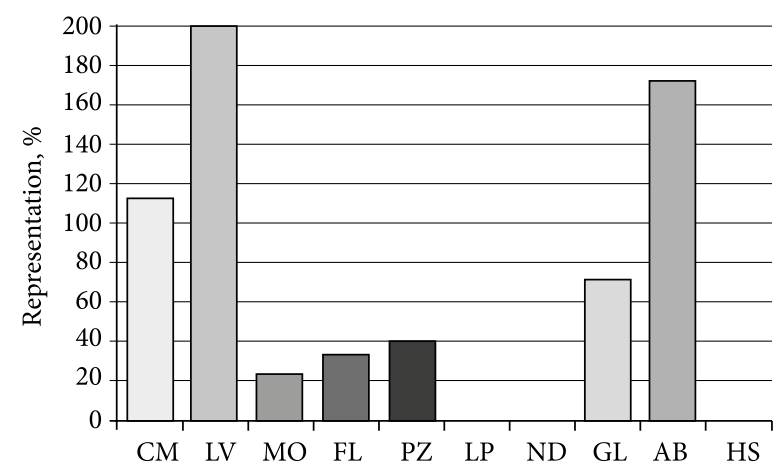

Fig. 6. Representation of soil types in the EU 28 and in biochar field trials. See Table 1 for the meaning of the soil codes. $100 \%$ means that the proportion of field sites is the same as the proportion of the agricultural area for the EU28. A representation value $>100 \%$ indicates over-representation, and a value $<100 \%$ indicates under-representation (Feb. 2015) 


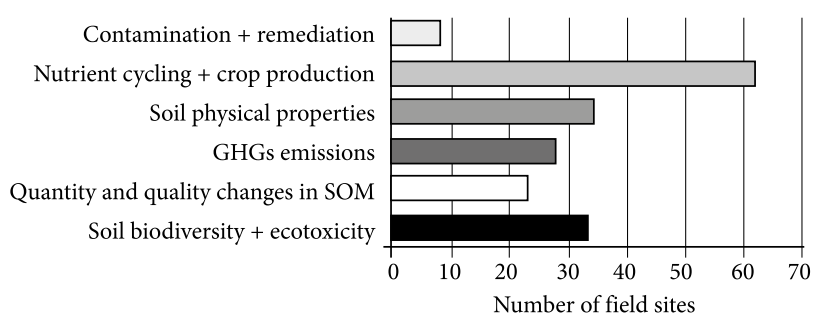

Fig. 7. Number of field sites that monitor variables related to the COST Action thematic groups (see Table 1)

\subsection{Thematic group representativeness}

Figure 7 shows the number of Biochar COST Action field sites that monitored variables related to the thematic groups at the time the survey was conducted (Table 1). The investigation of agronomic impacts of biochar application to soil appears to be the main objective of biochar field experimentation, as indicated by the greatest number of field sites that monitor variables within the Nutrient cycling + Crop production theme. This is likely a consequence of the initial claims surrounding the beneficial impact of biochar application to soil on crop yields - this claim being one of the main initial drivers for the biochar paradigm.

Approximately half the number of field sites that investigated yield effects, aimed to elucidate the mechanisms underlying biochar interactions with soil through investigating the impacts on soil physical properties. A similar number of studies also investigated the impacts on and interactions with soil biodiversity, including monitoring of ecotoxicological effects. Effects on soil organic matter and greenhouse gases were investigated at 25 sites. Contamination and remediation was the least investigated theme at our field sites with $<10$ field sites investigating biochar's potential in these areas.

Two to three themes are most commonly monitored at a Biochar COST Action field site (Table 1 and Suppl. Fig. 1). Roughly half as many field sites monitor four themes, while the extremes - just one theme or five to all six themes - are monitored by very few field sites.

\section{Discussion}

To build the knowledge base required to determine whether the implementation of biochar systems can be sustainable, it is imperative to achieve two types of representation: i) comprehensive representation, and ii) proportional representation. Comprehensive representation means that all options are explored, i.e. all potential biochars in all potential soils, climates, and agricultural systems, within pragmatic constraints. This is important regardless of whether the biochar-amended soil was improved for a specific purpose, or not. Potential undesired sideeffects need to be explored for all options to inform the specification and regulation of biochar systems to achieve sustainability. Proportional representation means that land that is more likely to receive biochar, should receive more research attention. Soils that cover a greater proportion of agricultural land, and soils that can be improved more for a specific function, are more likely to be used for biochar amendments.

\section{Biochar representativeness: production, properties, and application strategy}

Production technologies influence biochar properties, especially biochar carbon content, $\mathrm{O} / \mathrm{C}$ and $\mathrm{H} / \mathrm{C}_{\text {org }}$ ratios (Spokas et al. 2014; Lehmann, Joseph 2015; Schimmelpfennig, Glaser 2012), carbon stability and persistence (Peng et al. 2011; Lehmann et al. 2015), ash content (Deal et al. 2012; Lehmann, Joseph 2015), biochar $\mathrm{pH}$, pore space and potential for microbial enrichment (Lehmann, Joseph 2015; Wang et al. 2016). This is largely due to the transformative effect of the charring temperature and rate of heating (fast vs slow pyrolysis) on the nature of the carbon forms present; aliphatic- $\mathrm{C}$ decreases and aromaticity increases as the charring temperature increases, resulting in lower $\mathrm{O} / \mathrm{C}$ and $\mathrm{H} / \mathrm{C}_{\text {org }}$ ratios indicative of increased $\mathrm{C}$ stability and predicted persistence (Keiluweit et al. 2010; Peng et al. 2011; Brewer et al. 2012; Lehmann et al. 2015). Each production technology can be defined by temperature, rate of heating, etc., but the properties of the resulting biochar and its effect on crop productivity or soil quality is also highly dependent on the feedstock (Jeffery et al. 2011; Hansen et al. 2015). These technologies can only be rigorously compared for the same biomass feedstock (Brewer et al. 2012; Deal et al. 2012; Hansen et al. 2015). For our field sites, the most commonly employed production technology was fast pyrolysis (39\%), followed by slow pyrolysis (25\%) and retort kiln (23\%). This is a lower proportion of slow pyrolysis than other studies reported, e.g. 21 out of 24 trials in a meta-analysis of biochar-induced priming effects used slow pyrolysis (Wang et al. 2015), with three studies using biochar from fast pyrolysis production. The greater proportion of fast pyrolysis may reflect the growing interest to use biochar derived from biomass energy conversion installations in Europe. For the same feedstock, fast pyrolysis produces biochar with higher particle density and more volatiles than slow pyrolysis and gasification (Brewer et al. 2012; Lehmann, Joseph 2015). However, the heat transfer and kinetics of fast pyrolysis has the potential to result in unconverted biomass, which may be more susceptible to microbial degradation (Kuzyakov et al. 2009; Zimmerman 2010) resulting in lower C sequestration potential (Kuzyakov et al. 2009; Bruun et al. 2011). Increasing the temperature in fast pyrolysis systems can reduce the amount of unconverted biomass (Bruun et al. 2011; Lehmann, Joseph 2015). Gasification is usually 
carried out at higher temperatures $\left(>700^{\circ} \mathrm{C}\right)$ but is not considered to be an efficient producer of biochars per unit mass of feedstock. However, these are usually large-scale units with high overall production coupled with high energy output, and produce biochars with high stability and persistence suitable for carbon sequestration (Hansen et al. 2015).

Historic biochar systems applied biochar in combination with nutrient-rich organic waste materials such as sewage, compost, or manure (e.g. Glaser et al. 2001). In modern farming systems, the distance between organic matter source and application sites is much greater than in historical systems, commonly resulting in a negative cost-benefit perception and organic fertilisers not reaching the soils that need it most. This appears to be reflected in the majority of our field sites (77\%) receiving only pure biochar. Considering that there is growing evidence of pure biochar reducing the availability of $\mathrm{N}$ present in the soil (Bruun et al. 2012; Tammeorg et al. 2012), a greater proportion of field sites using nutrient-enriched biochar would be appropriate, also considering that this may not involve transportation costs of relatively dense fresh organic fertilisers. To avoid un-intended surface run-off and erosional losses of biochar from the soil surface, incorporation of biochar substrates in the soil is required and the majority of our field sites did incorporate the biochar to some degree (96\%). However, there is no scientific consensus on the optimum incorporation depth. From an agronomic perspective, as much as possible of the biochar should be located in the rooting zone when that biochar has been produced to maximise agronomic effects. However, rooting zones differ substantially for arable crops and even more for permanent crops, while deeper application also implies greater cost. The near equal 3-way split between the application depth categories (Fig. 3) seems appropriate considering the variation in rooting depths. The sizes of the field plots were similar as reported by Zhang et al. (2016), i.e. most commonly between $10-100 \mathrm{~m}^{2}$. The low proportion of larger experimental plots, particularly at the whole field or management unit (e.g. strip of field) scale $\left(<3 \%\right.$ of our field plots were $>100 \mathrm{~m}^{2}$ ), indicates that the upscaling to scales relevant for biochar systems and on-farm economics still needs to be developed.

\section{Environmental representativeness: climate, land use and soils}

The representativeness in relation to climatic zones is, to a large extent, linked to the importance of these zones in agricultural production. This explains the representativeness of the temperate climate as well as the need for additional covering of colder climates (Scandinavia, Baltic countries and Poland) and arid steppes in southern Europe. The complete lack of field-scale research in polar areas, on the other hand, probably does not need to be covered by extensive field experiments considering the negligible importance of these zones in agricultural production. The same can be concluded regarding land use. Similar to recently reported results of a worldwide study by Zhang et al. (2016), arable land use was well represented whereas pastures, grasslands, and forests need more research. The reason for such a spread is probably the higher economical return that is expected per tonne of added (rather expensive) biochar from arable crops than from pastures/ forests. For the same reason, biochar use may well become widespread first as a growing medium constituent in highvalue crops (see Kern et al. 2017, this issue) than as a fieldscale soil amendment material.

Three soil types were not represented at all: Leptosols, non-developed soils, and Histosols, which together cover $19 \%$ of the EU28 agricultural area. This was surprising considering that all three are prime candidates to potentially benefit from biochar amendment. Histosols are often low in $\mathrm{pH}$ and biochar's liming effect could improve nutrient availability to plants. Leptosols and nondeveloped soils are shallow soils with often low organic matter contents and biochar addition could improve soil depth as well as the CEC and water holding capacity. A possible explanation for the absence of Leptosols in our field sites may be that few Leptosols are in arable land use, with most in agroforestry, tree crop production or grassland. However, biochar may provide one component to "upgrade" some Leptosols to grow arable crops sustainably and in an economically viable way. Alternatively, biochar may be used to improve growing conditions for young trees in these soils. A meta-analysis of biochar and tree species showed a $41 \%$ increase in biomass in response to biochar globally (Thomas, Gale 2015) compared to a ca. $10 \%$ increase in arable crop yields globally (Jeffery et al. 2011; Liu et al. 2013). In our field sites, fertile arable soils that probably already produce yields close to the maximum potential, such as Luvisols and Albeluviols, are overrepresented even after considering their proportion of the EU28 agricultural area. From our analysis, we recommend a shift in focus from biochar field experiments on fertile soils to less fertile soils.

\section{Thematic representativeness}

Similar to Zhang et al. (2016), we found a very high proportion of field sites that monitor variables related to crop production. That soil physical properties and soil biodiversity, including ecotoxicology, are so well represented by field studies is testament to the growing recognition of the range of ecosystem services provided by soils beyond the normal crop yield function. Biochar has the potential to interact with many of these ecosystem services, in both positive and negative ways, and as such, a range 
of field trials are required to investigate the likely consequences of biochar application to soil on these services. One such ecosystem service provided by soil that biochar has been shown to interact with, is the climate change mitigation potential of soils. Biochar can interact with this service most obviously by increasing the amount of $\mathrm{C}$ stored in soils, thereby potentially ameliorating atmospheric concentrations of $\mathrm{CO}_{2}$. Further to this, biochar has been shown to interact with the three most important GHGs in a variety of ways (Cayuela et al. 2014; Sagrilo et al. 2015; Jeffery et al. 2016), as well as to potentially (positively or negatively) prime SOM turnover. With just under 30 field trials aiming to investigate the interactions between soil application of biochar and GHG fluxes from soils, and about 24 studies investigating interactions between biochar and SOM, it appears that these thematic areas are quite well represented. The least represented group in terms of field experiments is "Contamination and Remediation". This is likely a consequence of the remediation potential of biochar being one of the later recognised potential benefits of biochar. Owing to the wide range of soil contaminants in contaminated sites across Europe, this group is likely to be underrepresenting the real world situation. With $<10$ field sites, and each of those potentially investigating the interactions with the same types of contaminant, it appears likely that there are numerous contaminated sites within Europe that are not currently represented by field trials from this thematic group. However, further information is required on the contaminants currently under investigation to be able to better estimate how representative the current field sites are, and to identify which common soil contaminants are currently under-represented by biochar research in Europe. Our findings corroborate Zhang et al. (2016), who reported that of European field experiments with biochar, the majority are dealing with crop and plant production, followed by GHG mitigation and pollutant remediation. They did not distinguish the topics further, as we did (soil physical properties, SOM and soil biodiversity). The same prioritizing was reported throughout the world and it was considerably more pronounced in South America and Africa (Zhang et al. 2016), probably because of the more pressing issues of food security in these regions than in Europe.

\section{Limitations}

The database utilized for the representativeness analysis includes both published and unpublished data from biochar field studies. The advantage of including unpublished studies is that it allows for a more complete view of the current studies performed and therefore of the soil type, climate and variable investigated. On the other hand, we need to consider the possibility of overestimating the current representativeness as some of the studies may not be published and therefore information may not become available for better policy development. Another limitation of the current survey is that it is based on a voluntary participation. Great effort was put into the collection of as many field site experiments as possible, since within the Biochar COST Action network the survey was considered a priority. However, it must be considered that our effort is unlikely to have gathered every field site in Europe, and also more field sites may have started since the cutoff date (February, 2015). Another limitation is that land use change may not have been adequately captured, for example, if a particular field inserted into the database in 2013 subsequently had crop rotations or different land use, such changes may not have been updated to the database. This was the case with two long-term field experiments in Finland (Tammeorg et al. 2014a, 2014b).

This representativeness survey provides an overview of locations where field sites are located, relevant soil types, crops options, types of biochar (ranging from feedstock and carbonisation technologies) and their mode of incorporation and effect of biochar on measured parameters. However, the main messages in terms of effects of biochar observed in this representativeness survey needs to be considered within this context and cannot be generalised. Sakrabani et al. (2017, this issue) compared the field studies presented here with observed biochar effects in controlled, small scale conditions (such as pots, incubation and lysimeter studies) to provide some insight into generic mechanisms.

\section{Conclusions}

This study describes the ongoing biochar field experiments in Europe, gathered from the recently concluded biochar COST Action (TD1107), and identifies their representativeness regarding biochar production and properties, environmental variables, and thematic topics monitored. The submitted field experiments representatively cover the different biochar production technologies and application strategies (e.g. depth) reported within a European context.

Experiments utilising woody feedstock applied without organic or inorganic fertiliser are over-represented, especially considering the availability of crop residues, manures, and other organic waste streams and the efforts to move towards a zero waste economy. While the main climatic zones and arable land use were well represented, grasslands and forests need more research. This observation was supported by soil type representativeness, which showed over-representation of fertile arable soils vs. under-representation of shallow unfertile soils, many of which are likely in agroforestry or forest plantation land use. Thematically, the most studied theme was crop production. However, other themes that can provide evidence 
of mechanisms, as well as potential undesired side-effects, were relatively well represented. Soil contamination and remediation was the least represented theme, and further work is needed to identify which specific contaminants, or mixtures of contaminants, need more research attention. We also propose that in order to communicate the strengths and drawbacks of the biochar practice to local stakeholders (especially farmers), it would be advisable to have at least one long-term biochar field experiment in each European country (currently only half of the EU28 countries were represented).

\section{Acknowledgements}

The authors are grateful to the EU COST Action TD1107 (Biochar as option for sustainable resource management) for funding the meetings that helped to enable this work. We also wish to acknowledge the Portuguese Foundation for Science and Technology (FCT) for the fellowships of A.C. Bastos (SFRH/BPD/98231/2013) and F.G.A. Verheijen (SFRH/BPD/107913/2015), the financial support to CESAM [UID/AMB/50017/2013], to FCT/MEC through national funds and the co-funding by FEDER, within PT2020 Partnership Agreement and Compete 2020. The authors are very indebted to Jan Sorensen who was extremely helpful in converting the Excel version of the survey into an online version that could be easily edited, stored and used to retrieve information. Johannes Harter was also very instrumental in retrieving information for the online version of the survey and collating it into a format that authors could use for this publication. Adam O'Toole's contribution in formulating the first steps towards a Google Map that shows locations of field sites is very much appreciated by the authors.

\section{References}

Abrol, V.; Ben-Hur, M.; Verheijen, F. G. A.; Keizer, J. J.; Martins, M. A. S.; Tenaw, H.; Tchehansky, L.; Graber, E. 2016. Biochar effects on soil water infiltration and erosion under seal formation conditions: rainfall simulation experiment, Journal of Soils and Sediments 16: 2709-2719. https://doi.org/10.1007/s11368-016-1448-8

Ameloot, N.; Graber, E. R.; Verheijen, F. G. A.; De Neve, S. 2013. Interactions between biochar stability and soil organisms: review and research needs, European Journal of Soil Science 64(4): 379-390. https://doi.org/10.1111/ejss.12064

Brewer, C. E.; Hu, Y. Y.; Schmidt-Rohr, K.; Loynachan, T. E.; Laird, D. A.; Brown, R. C. 2012. Extent of pyrolysis impacts on fast pyrolysis biochar properties, Journal of Environmental Quality 41(4): 1115-1122.

https://doi.org/10.2134/jeq2011.0118

Brewer, C. E.; Chuang, V. J.; Masiello, C. A.; Gonnermann, H.; Gao, X.; Dugan, B.; Driver, L. E.; Panzacchi, P.; Zygourakis, K.; Davies, C. A. 2014. New approaches to measuring biochar density and porosity, Biomass \& Bioenergy 66: 176185. https://doi.org/10.1016/j.biombioe.2014.03.059
Bruun, E. W.; Hauggaard-Nielsen, H.; Ibrahim, N.; Egsgaard, H.; Ambus, P.; Jensen, P. A.; Dam-Johansen, K. 2011. Influence of fast pyrolysis temperature on biochar labile fraction and short-term carbon loss in a loamy soil, Biomass and Bioenergy 35(3): 1182-1189.

https://doi.org/10.1016/j.biombioe.2010.12.008

Bruun, E. W.; Ambus, P.; Egsgaard, H.; Hauggaard-Nielsen, H. 2012. Effects of slow and fast pyrolysis biochar on soil C and $\mathrm{N}$ turnover dynamics, Soil Biology \& Biochemistry 46: 73-79. https://doi.org/10.1016/j.soilbio.2011.11.019

Deal, C.; Brewer, C. E.; Brown, R. C.; Okure, M. A. E.; Amoding, A. 2012. Comparison of kiln-derived and gasifier-derived biochars as soil amendments in the humid tropics, Biomass \& Bioenergy 37: 161-168. https://doi.org/10.1016/j.biombioe.2011.12.017

Eckelmann, W.; Baritz, R.; Bialousz, S.; Bielek, P.; Carre, F.; Houšková, B.; Jones, R. J. A.; Kibblewhite, M. G.; Kozak, J.; Le Bas, C.; Tóth, G.; Tóth, T.; Várallyay, G.; Yli Halla, M.; Zupan, M. 2006. Common Criteria for Risk Area Identification according to Soil Threats. European Soil Bureau Research Report No. 20, EUR 22185 EN, 94. Office for Official Publications of the European Communities, Luxembourg.

EEA. 2016. Corine Land Cover 2006 raster data Version 16 (04/2012) - Raster data on land cover for the CLC2006 inventory. Data Created 07 May 2012, Published 11 Jun 2012, Last modified 08 Dec 2015, 02:32 PM.

ESDB v2.0: The European Soil Database distribution version 2.0. European Commission and the European Soil Bureau Network, CD-ROM, EUR 19945 EN, 2004.

European Biochar Research Network [online] n.d. [cited 1 February 2017]. Available from Internet: http://cost.europeanbiochar.org

Cayuela, M. L.; Van Zwieten, L.; Singh, B. P.; Jeffery, S.; Roig, A.; Sánchez-Monedero, M. A. 2014. Biochar's role in mitigating soil nitrous oxide emissions: a review and meta-analysis, $A g$ riculture, Ecosystems \& Environment 191: 5-16. https://doi.org/10.1016/j.agee.2013.10.009

Glaser, B.; Haumaier, L.; Guggenberger, G.; Zech, W. 2001. The "Terra Preta" phenomenon: a model for sustainable agriculture in the humid tropics, Naturwissenschaften 88(1): 37-41. https://doi.org/10.1007/s001140000193

Glaser, B.; Lehmann, J.; Zech, W. 2002. Ameliorating physical and chemical properties of highly weathered soils in the tropics with charcoal - a review, Biology and Fertility of Soils 35(4): 219-230. https://doi.org/10.1007/s00374-002-0466-4

Glaser, B.; Wiedner, K.; Seelig, S.; Schmidt, H. P.; Gerber, H. 2015. Biochar organic fertilizers from natural resources as substitute for mineral fertilizers, Agronomy for Sustainable Development 35(2): 667-678. https://doi.org/10.1007/s13593-014-0251-4

Gurwick, N. P.; Moore, L. A.; Kelly, C.; Elias, P. 2013. A systematic review of biochar research, with a focus on its stability in situ and its promise as a climate mitigation strategy, PLoS ONE 8(9): e75932. https://doi.org/10.1371/journal.pone.0075932

Hansen, V.; Müller-Stöver, D.; Ahrenfeldt, J.; Holm, J. K.; Henriksen, U. B.; Hauggaard-Nielsen, H. 2015. Gasification biochar as a valuable by-product for carbon sequestration and soil amendment, Biomass and Bioenergy 72: 300-308. https://doi.org/10.1016/j.biombioe.2014.10.013 
Jeffery, S.; Verheijen, F. G. A.; Van Der Velde, M.; Bastos, A. C. 2011. A quantitative review of the effects of biochar application to soils on crop productivity using meta-analysis, Agriculture, Ecosystems and Environment 144(1): 175-187. https://doi.org/10.1016/j.agee.2011.08.015

Jeffery, S.; Verheijen, F. G. A.; Kammann, C.; Abalos, D. 2016. Biochar effects on methane emissions from soils: a meta-analysis, Soil Biology and Biochemistry 101: 251-258. https://doi.org/10.1016/j.soilbio.2016.07.021

Keiluweit, M.; Nico, P. S.; Johnson, M. G.; Kleber, M. 2010. Dynamic molecular structure of plant biomass-derived black carbon (biochar), Environmental Science \& Technology 44(4): 1247-1253. https://doi.org/10.1021/es9031419

Kern, J.; Tammeorg, P.; Shanskiy, M.; Sakrabani, R.; Knicker, H.; Kammann, C.; Tuhkanen, E. M.; Smidth, G.; Prasadi, M.; Tiilikkala, K.; Sohi, S.; Gasco, G.; Glaser, B. 2017. Synergistic use of peat and char materials in growing media - one option reducing the pressure on peatlands?, Journal of Environmental Engineering and Landscape Management (this issue). https://doi.org/10.3846/16486897.2017.1284665

Kuzyakov, Y.; Subbotina, I.; Chen, H.; Bogomolova, I.; Xu, X. 2009. Black carbon decomposition and incorporation into soil microbial biomass estimated by 14C labeling, Soil Biology and Biochemistry 41(2): 210-219. https://doi.org/10.1016/j.soilbio.2008.10.016

Lehmann, J. 2007. A handful of carbon, Nature 447: 143-144. https://doi.org/10.1038/447143a

Lehmann, J.; Abiven, S.; Kleber, M.; Genxing, P.; Singh, B. P.; Sohi, S.; Zimmerman, A. 2015. Persistence of biochar in soil, in J. Lehmann, S. Joseph (Eds.). Biochar for Environmental Management: Science, Technology and Implementation. London and New York: Earthscan, 235-282.

Lehmann, J.; Joseph, S. (Eds.). 2015. Biochar for environmental management: science, technology and implementation. London and New York: Earthscan.

Liu, X.; Zhang, A.; Ji, C.; Joseph, S.; Bian, R.; Li, L.; Pan, G.; PazFerreiro, J. 2013. Biochar's effect on crop productivity and the dependence on experimental conditions - a meta-analysis of literature data, Plant Soil 373.

https://doi.org/10.1007/s11104-013-1806-x

Peel, M. C.; Finlayson, B. L.; McMahon, T. A. 2007. Updated world map of the Köppen-Geiger climate classification, $\mathrm{Hy}$ drology and Earth System Sciences 11: 1633-1644. https://doi.org/10.5194/hess-11-1633-2007

Peng, X.; Ye, L. L.; Wang, C. H.; Zhou, H.; Sun, B. 2011. Temperature- and duration-dependent rice straw-derived biochar: characteristics and its effects on soil properties of an Ultisol in southern China, Soil and Tillage Research 112(2): 159-166. https://doi.org/10.1016/j.still.2011.01.002

Sagrilo, E.; Jeffery, S.; Hoffland, E.; Kuyper, T. W. 2015. Emission of $\mathrm{CO}_{2}$ from biochar-amended soils and implications for soil organic carbon, Global Change Biology and Bioenergy 7(6): 1294-1304. https://doi.org/10.1111/gcbb.12234

Sakrabani, R.; Kern, J.; Mankasing, U.; Zavalloni, C.; Zanchettine, G.; Bastos, A. C.; Tammeorg, P.; Jeffery, S.; Glaser, B.; Verheijen, F. G. A. 2017. Representativeness of European biochar research: part II - pot and laboratory studies, Journal of Environmental Engineering and Landscape Management (this issue).

Schimmelpfennig, S.; Glaser, B. 2012. One step forward toward characterization: some important material properties to distinguish biochars, Journal of Environmental Quality 41: 1001-1013. https://doi.org/10.2134/jeq2011.0146

Spokas, K. A.; Novak, J. M.; Masiello, C. A.; Johnson, M. G.; Colosky, E. C.; Ippolito, J. A.; Trigo, C. 2014. Physical disintegration of biochar: an overlooked process, Environmental Science \& Technology Letters 1(8): 326-332. https://doi.org/10.1021/ez500199t

Tammeorg, P.; Brandstaka, T.; Simojoki, A.; Helenius, J. 2012. Nitrogen mineralisation dynamics of meat bone meal and cattle manure as affected by the application of softwood chip biochar in soil, Earth and Environmental Science Transactions of the Royal Society of Edinburgh 103(01): 19-30. https://doi.org/10.1017/S1755691012000047.

Erratum Earth and Environmental Science Transactions of the Royal Society of Edinburgh 105: 72.

https://doi.org/10.1017/s1755691012000047

Tammeorg, P.; Simojoki, A.; Mäkelä, P.; Stoddard, F. L.; Alakukku, L.; Helenius, J. 2014a. Biochar application to a fertile sandy clay loam in boreal conditions: effects on soil properties and yield formation of wheat, turnip rape and faba bean, Plant and Soil 374(1-2): 89-107.

http://dx.doi/org/10.1007/s11104-013-1851-5.

Erratum Plant and Soil 379: 389-390.

https://doi.org/10.1007/s11104-014-2098-5

Tammeorg, P.; Simojoki, A.; Mäkelä, P.; Stoddard, F. L.; Alakukku, L.; Helenius, J. 2014b. Short-term effects of biochar on soil properties and wheat yield formation with meat bone meal and inorganic fertiliser on a boreal loamy sand, Agriculture, Ecosystems \& Environment 191: 108-116. https://doi.org/10.1016/j.agee.2014.01.007

Tammeorg, P.; Bastos, A. C.; Jeffery, S.; Rees, F.; Kern, J.; Graber, E.; Ventura, M.; Kibblewhite, M.; Amaro, A.; Budai, A.; Cordovil, C. M. d. S.; Domene, X.; Gardin, G.; Gasco, G.; Horak, J.; Kammann, C.; Kondrlova, E.; Laird, D.; Loureiro, S.; Martins, M. A. S.; Panzacchi, P.; Prasad, M.; Prodana, M.; Puga, A. P.; Ruysschaert, G.; Sas-Paszt, L.; Silva, F. C.; Teixeira, W. G.; Tonon, G.; Vedove, G. D.; Zavalloni, C.; Glaser, B.; Verheijen, F. G. A. 2017. Biochars in soils: towards the required level of scientific understanding, Journal of Environmental Engineering and Landscape Management (this issue). https://doi.org/10.3846/16486897.2016.1239582

Thomas, S. C.; Gale, N. 2015. Biochar and forest restoration: a review and meta-analysis of tree growth responses, New Forests 46: 931-946. https://doi.org/10.1007/s11056-015-9491-7

Verheijen, F. G. A, Jeffery, S.; Bastos A. C., Van Der Velde, M.; Diafas, I. 2010. Biochar application to soils - a critical scientific review of effects on soil properties, processes and functions. European Commission, Luxembourg. http://publications.jrc. ec.europa.eu/repository/handle/JRC55799

Verheijen, F. G. A.; Montanarella, L.; Bastos, A. C. 2012. Sustainability, certification, and regulation of biochar, Pesquisa Agropecuária Brasileira 47(5): 649-653. https://doi.org/10.1590/S0100-204X2012000500003

Verheijen, F. G. A.; Jeffery, S.; van der Velde, M.; Penizek V.; Beland, M.; Bastos, A. C.; Keizer, J. J. 2013. Reductions in soil surface albedo as a function of biochar application rate: implications for global radiative forcing, Environmental Research Letters 8(4): 1-7. https://doi.org/10.1088/1748-9326/8/4/044008

Verheijen, F. G. A.; Graber, E. R.; Ameloot, N.; Bastos, A. C.; Sohi, S.; Knicker, H. 2014. Biochars in soils: new insights and emerging research needs introduction, European Journal of Soil Science 65: 22-27. https://doi.org/10.1111/ejss.12127 
Verheijen, F. G. A.; Bastos, A. C.; Schmidt, H. P.; Brandão, M.; Jeffery, S. 2015. Biochar sustainability and certification in J. Lehmann, S. Joseph (Eds.). Biochar for environmental management, science, technology and implementation. 2nd ed. London and New York: Earthscan.

Wang, J.; Xiong, Z.; Kuzyakov, Y. 2015. Biochar stability in soil: meta-analysis of decomposition and priming effects, $G C B$ Bioenergy 8(3): 512-523. https://doi.org/10.1111/gcbb.12266

Wang, J.; Dokohely, M. E.; Xiong, Z.; Kuzyakov, Y. 2016. Contrasting effects of aged and fresh biochars on glucose-induced priming and microbial activities in paddy soil, Journal of Soils and Sediments 16(1): 191-203.

https://doi.org/10.1007/s11368-015-1189-0
Zhang, D.; Yan, M.; Niu, Y.; Liu, X.; van Zwieten, L.; Chen, D.; Bian, R.; Cheng, K.; Li, L.; Joseph, S.; Zheng, J.; Zhang, X.; Zheng, J.; Crowley, D.; Filley, T. R.; Pan, G. 2016. Is current biochar research addressing global soil constraints for sustainable agriculture?, Agriculture, Ecosystems \& Environment 226: 25-32. https://doi.org/10.1016/j.agee.2016.04.010

Zimmerman, A. R. 2010. Abiotic and microbial oxidation of laboratory-produced black carbon (biochar), Environmental Science \& Technology 44(4): 1295-1301. https://doi.org/10.1021/es903140c

Frank G. A. VERHEIJEN, PhD, research fellow of the Portuguese Science Foundation (FCT), Centre for Environmental and Marine Studies (CESAM), University of Aveiro, Portugal. 24 publications in int. peer-reviewed journals, 7 major European reports, 7 books, 6 book chapters. 2,249 citations; h-index 16 (Google Scholar).

Utra MANKASINGH, PhD, Research Fellow in the Faculty of Life and Environmental Sciences at the University of Iceland. 6 publications in international peer reviewed journals, 3 major reports, 159 citation; h-index 4 (Google Scholar).

Vit PENIZEK, PhD, associate professor, Czech University of Life Sciences Prague, Department of Soil Science and Soil Protection, Prague, Czech Republic, 39 publications in int. peer-reviewed journals, 365 citations, h-index 11 (Google Scholar).

Pietro PANZACCHI, PhD, Postdoctoral researcher in Forest Ecology, Faculty of Science and Technology, Free University of Bolzano, 10 peer-reviewed articles in international scientific journals, 274 citations, h-index 8 (Google Scholar).

Bruno GLASER, PhD, Professor of Soil Biogeochemistry, Institute of Agronomy and Nutritional Sciences, Martin Luther University Halle-Wittenberg, Germany, 141 peer-reviewed articles in scientific journals, h-index 39 (WoS).

Simon JEFFERY, PhD, Senior Lecturer at Harper Adams University, Department of Crop and Environment Sciences, 24 publications in int. peer-reviewed journals, 4 major European reports, 2 books, 1 book chapter. 1,909 citations, h-index 16 (Google Scholar).

Ana Catarina BASTOS, $\mathrm{PhD}$, research fellow of the Portuguese Science Foundation (FCT), at Department of Biology and Centre for Environmental and Marine Studies (CESAM), University of Aveiro, Portugal. 21 publications in international peer-reviewed journals, 1 European Commission report, 4 book chapters. 1552 citations; h-index 12 (Google Scholar).

Priit TAMMEORG, DSc, Postdoctoral Researcher in Agroecology, Dept of Agricultural Sciences, University of Helsinki, 9 peer-reviewed articles in international scientific journals, h-index 6 (WoS).

Jürgen KERN, PhD, Senior Scientist of Biogeochemistry, Leibniz Institute for Agricultural Engineering Potsdam-Bornim, Germany, 1211 citations, h-index 16 (Google Scholar).

Costanza ZAVALlONI, PhD, Assistant Professor in plant science in the Agricultural Studies program, California State University Stanislaus, Turlock, 19 peer-reviewed articles in international scientific journals, 1 book chapter, 514 citations, h-index 11 (Google Scholar).

Giulia ZANCHETTIN, MSc graduate student in Ecology and Soil Science and was funded under the Short Term Scientific Mission (within the Biochar COST Action) to analyse the representativeness dataset.

Ruben SAKRABANI, PhD, Senior Lecturer in Soil Chemistry, Cranfield Soil and Agrifood Institute, Cranfield University, 30 peer-reviewed articles, h-index 10 (Google Scholar). 